\title{
Exercise training program in children with lower-limb amputation
}

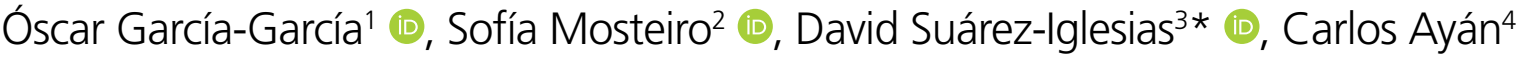

\section{SUMMARY}

OBJECTIVE: Few physical exercise programs for children with limb loss have been described in detail recently. We provided information regarding the characteristics and effectiveness of an alternative rehabilitation exercise developed for children with lower-limb amputation. METHODS: An 8-year-old boy with a below-knee amputation and a 9-year-old bilateral amputee girl performed an exercise program of one 2-h session per week for 20 weeks, aimed at developing muscular strength and coordination. Walking ability and walking speed were assessed by using the L-test of functional mobility and 10-m walk test, respectively. Mechanical and neuromuscular muscle function was assessed by using tensiomyography.

RESULTS: In case 1 , a decrement of $9.5 \%$ and $10.5 \%$ was found in the L-test (42 s vs. $38 \mathrm{~s}$ ) and in the $10-\mathrm{m}$ test (19 s vs. $17 \mathrm{~s}$ ) scores, respectively. In case 2, walking ability remained unchanged (L-test score: $38 \mathrm{~s}$ ), while a $5.2 \%$ reduction in walking speed was observed (10-m test score: 19 s vs. 18 s). No relevant changes were observed in the muscular tone in both cases.

CONCLUSIONS: Practitioners should be aware that, contrary to what could be expected, a multidisciplinary training program held once per week for 5 months had a minimal impact on the gait pattern and neuromuscular function of two children with lower-limb amputation. KEYWORDS: Amputees. Child. Exercise. Gait. Muscle tonus.

\section{INTRODUCTION}

Children with lower-limb amputation must adopt specific compensation strategies to overcome the limitations associated with amputation in their daily activities, mainly due to the loss of muscle mass and proprioception functions ${ }^{1}$. In fact, scientific evidence has shown that in children, the amputation of a lower limb can result in several biomechanical (i.e., changes on the level of muscular co-contraction, gait asymmetry, and increased loading of both lower limbs) ${ }^{1}$ and physiological limitations (i.e., increased oxygen demand and higher heart rate while walking) ${ }^{2,3}$. Similarly, kinematic and spatiotemporal lower limb asymmetries can be present because of loss of muscle function ${ }^{4}$. As a result, children with lower-limb amputation show impaired balance, decreased postural control, slower walking patterns, and increased physiological energy costs ${ }^{4,5}$. In addition, it has been suggested that some of these limitations could lead to degenerative joint diseases in the long term ${ }^{6,7}$.

Therefore, rehabilitation strategies are needed for this population, especially those aimed at normalizing gait patterns and restoring muscle function. In this regard, physical exercise has been confirmed as a useful therapeutic approach in lower-limb amputees given that its performance can lead to significant improvements in their fitness level and locomotor skills ${ }^{8,9}$. However, the vast majority of studies that provide

\footnotetext{
'Universidade de Vigo, Faculty of Education and Sports Sciences, Laboratory of Sports Performance, Physical Condition and Wellness - Pontevedra, Spain. ${ }^{2}$ Absolute Wellness Center - A Estrada, Spain.

3Universidad de León, Institute of Biomedicine, Faculty of Physical Activity and Sports Valoración de la Condición Física en relación con la Salud, el Entrenamiento y el Rendimiento Deportivo Research Group - León, Spain.

${ }^{4}$ Universidade de Vigo, Well-Move Research Group, Galicia Sur Health Research Institute, Departamento de Didácticas Especiais - Pontevedra, Spain. *Corresponding author: dsuai@unileon.es

Conflicts of interest: the authors declare that there are no conflicts of interest. Funding: none.

Received on September 04, 2020. Accepted on September 11, 2020.
} 
information about the feasibility, characteristics, and effects of physical exercise training programs in people with lower-limb amputation have been focused on adult populations, and there are very few reports describing this rehabilitation process in pediatric populations. This lack of research is a matter of concern for several reasons. First, according to the authors' knowledge, there is no clear consensus on the best practice guideline regarding the physical therapy process that should be carried out by a child following lower-limb amputation. Second, children have complex and specific rehabilitation needs that are distinguishable from those of adults (i.e., expected skeletal growth, functional demand on the locomotor system and prosthesis, appositional bone stump overgrowth, and psychological challenges ${ }^{10}$, implying that they require tailored rehabilitation programs that are different from the ones usually carried out with adult populations ${ }^{11}$. Finally, it is difficult to engage children in prescribed exercise rehabilitation programs, due to the inclusion of repetitive and often tedious tasks during the exercises, which suggests the need for exploring the efficacy of other dynamic and more attractive therapy approaches for younger amputees $^{12}$. Under these circumstances, this case study aims at providing information regarding the effectiveness of an alternative rehabilitation exercise intervention on walking ability and mechanical and neuromuscular functions of two children with lower-limb amputation.

\section{METHODS}

\section{Participants}

Two children with lower-limb amputation who were referred to rehabilitation agreed to take part in this study. Both children were established walkers who used their prostheses every day for more than 4 years. Case 1 was a boy (age: 8 years, height: $131 \mathrm{~cm}$, and weight: $31 \mathrm{~kg}$ ), with a below-knee amputation, who met with an accident with a motor vehicle when he was 2 years old. Case 2 was a bilateral amputee girl (age: 9 years, height: $139 \mathrm{~cm}$, and weight: $33 \mathrm{~kg}$ ), due to meningitis that she suffered at the age of 5 . She had a lower-limb amputation at the transtibial (left) and knee disarticulation levels (right). Written informed consent was obtained from both the parents and the children, who consented to the experimental measurements. The protocol of this study was approved by the Local Ethics Committee, and this study was conducted in accordance with the Declaration of Helsinki.

\section{Procedures}

Both children took part in an exercise training program performed once a week for 20 weeks. The sessions were 2-h-long and included exercises aimed at developing muscular strength and coordination. The first part of the session was based on the performance of core training (CT) exercises. Initially, the children performed one set of six exercises, for $20 \mathrm{~s}$ each. As the intervention progressed, the number of exercises increased as well as the number of sets. The children ended the program by performing 3 sets of 10 exercises, with a 2 -min resting interval between them. The second part of the session was focused on coordination exercises and lower-limb strengthening exercises. The children progressed from performing 1 set of 10 exercises to 3 sets, with a 1-min resting interval between them. Drills involved in a typical training session were as follows: (a) CT: (i) forearm plank with toes tucked under $(3 \times 20 \mathrm{~s}$ with $2 \mathrm{~min}$ recovery), (ii) bent-knee forearm side plank $(3 \times 20$ s each side with 2 min recovery), (iii) Bosu $\mathrm{V}$-sit and pectoralis activation with ring $(3 \times 20 \mathrm{~s}$ with $2 \mathrm{~min}$ recovery), and (iv) bridging on a mat with the pelvis raised off the mat ( $3 \times 20 s$ with 2 min recovery); (b) coordination: (i) stepping over the mini-hurdles, the prosthetic lower limb is not abducted $(5 \times 10$ mini-hurdles with $2 \mathrm{~min}$ recovery) and (ii) stepping up and down in a forward direction $(3 \times 10$ reps each lower limb with 2 min recovery); and (c) strength: (i) lateral squat with hands at the waist $(3 \times 10$ reps with 2 min recovery), (ii) lateral squat walk $(3 \times 15 \mathrm{~m}$ with $2 \mathrm{~min}$ recovery), (iii) $1 \mathrm{~kg}$ medicine ball half squat throw $(3 \times 10$ reps with 1 min recovery), and (iv) standing leg abduction with resistance band ( $3 \times 10$ reps with 1 min recovery).

All sessions were performed on a sport facility and were designed and supervised by an exercise and rehabilitation specialist with experience in the prescription of physical exercise for people with lower-limb amputations.

\section{Measurements}

Walking ability and walking speed were assessed by the L-test of functional mobility and $10-\mathrm{m}$ walk test $(10 \mathrm{MWT})^{13}$, respectively. Mechanical and neuromuscular muscle functions were assessed by tensiomyography (TMG), a noninvasive method to measure radial muscle belly displacement of the biceps femoris (BF) and rectus femoris (RF) in the lower limbs of both children. The assessment followed the protocol suggested by Simunic et al. ${ }^{14}$ Each measurement involved recording the following parameters of involuntary isometric contraction produced by the electrical stimulus: $\mathrm{Dm}$ is the maximum radial muscle belly displacement of the muscle measured in $\mathrm{mm}$, Tc is the time measured in ms from $10 \%$ to $90 \%$ of $\mathrm{Dm}$ of the muscle, and radial displacement velocity $(\mathrm{Vrd})$ is the rate $(\mathrm{mm} / \mathrm{s})$ between the radial displacement occurring during the time period of Tc $(\mathrm{Dm} 80)$ and Tc $(\mathrm{Dm} 80 / \mathrm{Tc})$. 


\section{RESULTS}

Both children completed a total of 20 sessions. TMG results are presented in Table 1 for both participants. In case 1, RF showed a decrease in muscle tone in both lower limbs, being greater in the amputated lower limb (an increase of $20.8 \%$ of the $\mathrm{Dm}$ ). In the $\mathrm{BF}$ of the amputated lower limb, a reduction in muscle tone was also observed (an increase of $62.5 \%$ of the $\mathrm{Dm})$, which was increased in the opposite lower limb. In case 2 , an increase in muscle tone was observed in the RF of the knee-disarticulated limb (right) and a reduction in the RF of the transtibial amputated limb. No changes were observed in the BF of both lower limbs.

Moreover, in case 1, there was an increase in Vrd in the muscles tested in both lower limbs, except for BF in the nonamputated side. In case 2, the Vrd tested in the RF decreased in the knee-disarticulated limb and increased in the transtibial amputated limb. No relevant changes were observed in the Vrd of the BF.

Regarding walking ability and walking speed, the observed changes were of little relevance in both children. In case 1, a decrement of $9.5 \%$ and $10.5 \%$ was found in the L-test ( 42 vs. $38 \mathrm{~s}$ ) and in the $10-\mathrm{m}$ test (19 vs. $17 \mathrm{~s}$ ) scores, respectively. In case 2 , walking ability remained unchanged (L-test score: $38 \mathrm{~s}$ ), while a $5.2 \%$ reduction in walking speed was observed (10-m test score: 19 vs. $18 \mathrm{~s})$.

\section{DISCUSSION}

In this study, a training program based on the performance of strengthening and coordination exercises has shown to be feasible for being carried out by two children with lower-limb amputation. However, its effects on the walking ability and walking speed were modest at best. One explanation for this lack of effects could be the characteristics of the training program, in which specific balance exercises were underrepresented. In this intervention, CT was expected to lead to a better walking ability and walking speed through balance improvements. In people with reduced mobility, it has been suggested that CT can reduce balance impairment through improvements in trunk muscle strength on the basis that a stable core facilitates the transfer of torque and angular momentum between the lower and upper extremities, providing proximal stability for distal mobility ${ }^{15}$. In fact, previous study has shown that the performance of CT has resulted in balance improvements in people with impaired gait performance ${ }^{16}$. According to the present findings, it seems that CT does not have these effects on these two children with lower-limb amputation. Finally, it should be noted that the impact of the program on walking ability and walking speed was slightly different since a positive trend was observed in the boy who had suffered an amputation below the knee, while no changes were observed in the girl with transtibial amputation. These findings could be related to the different

Table 1. Assessments of descriptive tensiomyography parameters of preintervention and postintervention.

\begin{tabular}{|c|c|c|c|c|c|c|c|}
\hline \multicolumn{8}{|c|}{ Case 1} \\
\hline Parameters & Side & RF pre & RF post & Dif\% & BF pre & BF post & Dif\% \\
\hline \multirow{2}{*}{ TC } & $\mathrm{R}$ & $27.8 \mathrm{~ms}$ & $24.5 \mathrm{~ms}$ & -11.8 & $26.2 \mathrm{~ms}$ & $35.4 \mathrm{~ms}$ & 35.1 \\
\hline & L & $52.8 \mathrm{~ms}$ & $43.7 \mathrm{~ms}$ & -17.2 & $33.1 \mathrm{~ms}$ & $26.4 \mathrm{~ms}$ & -20.2 \\
\hline \multirow{2}{*}{ Dm } & $\mathrm{R}$ & $4.8 \mathrm{~mm}$ & $5.8 \mathrm{~mm}$ & 20.8 & $7.2 \mathrm{~mm}$ & $11.7 \mathrm{~mm}$ & 2.5 \\
\hline & L & $8.6 \mathrm{~mm}$ & $9.3 \mathrm{~mm}$ & 8.1 & $8.2 \mathrm{~mm}$ & $5.5 \mathrm{~mm}$ & -32.9 \\
\hline \multirow{2}{*}{ Vrd } & $\mathrm{R}$ & $138.1 \mathrm{~mm} / \mathrm{s}$ & $189.3 \mathrm{~mm} / \mathrm{s}$ & 27 & $219.8 \mathrm{~mm} / \mathrm{s}$ & $264.4 \mathrm{~mm} / \mathrm{s}$ & 16.8 \\
\hline & $\mathrm{L}$ & $130.3 \mathrm{~mm} / \mathrm{s}$ & $170.2 \mathrm{~mm} / \mathrm{s}$ & 23.4 & $198.1 \mathrm{~mm} / \mathrm{s}$ & $166.6 \mathrm{~mm} / \mathrm{s}$ & -18.9 \\
\hline \multicolumn{8}{|c|}{ Case 2} \\
\hline Parameters & Side & RF pre & RF post & Dif\% & BF pre & BF post & Dif\% \\
\hline \multirow{2}{*}{ Tc } & $\mathrm{R}$ & $94.2 \mathrm{~ms}$ & $48.4 \mathrm{~ms}$ & -48.6 & $45.6 \mathrm{~ms}$ & $51.8 \mathrm{~ms}$ & 13.5 \\
\hline & L & $22.0 \mathrm{~ms}$ & $22.1 \mathrm{~ms}$ & 0 & $47.1 \mathrm{~ms}$ & $49.3 \mathrm{~ms}$ & 4.6 \\
\hline \multirow{2}{*}{ Dm } & $R$ & $3.1 \mathrm{~mm}$ & $1.2 \mathrm{~mm}$ & -61.2 & $3.4 \mathrm{~mm}$ & $3.5 \mathrm{~mm}$ & 2.9 \\
\hline & L & $3.0 \mathrm{~mm}$ & $4.3 \mathrm{~mm}$ & 43.3 & $6.4 \mathrm{~mm}$ & $6.3 \mathrm{~mm}$ & -1.5 \\
\hline \multirow{2}{*}{ Vrd } & $R$ & $26.3 \mathrm{~mm} / \mathrm{s}$ & $19.8 \mathrm{~mm} / \mathrm{s}$ & -32.8 & $59.6 \mathrm{~mm} / \mathrm{s}$ & $54.0 \mathrm{~mm} / \mathrm{s}$ & -10.2 \\
\hline & L & $109.0 \mathrm{~mm} / \mathrm{s}$ & $155.6 \mathrm{~mm} / \mathrm{s}$ & 29.9 & $108.7 \mathrm{~mm} / \mathrm{s}$ & $102.2 \mathrm{~mm} / \mathrm{s}$ & -6.3 \\
\hline
\end{tabular}

Dm: maximum radial muscle belly displacement of the muscle; Tc: time from $10 \%$ to $90 \%$ of Dm of the muscle; Vrd: radial displacement velocity; RF: rectus femoris; BF: biceps femoris; Dif\%: difference percentage; R: right; L: left. 
gait patterns observed between children with an amputation distal to the knee or above the knee ${ }^{17}$ and imply that rehabilitation strategies for children with lower-limb amputation could differ according to the amputation level.

After the intervention, a decrease in muscle tone was observed in the amputated lower limb in case 1 , which can be considered as a positive effect of the intervention. However, in case 2, this effect was only evident in the RF of the transtibial amputated limb. Also, in case 1, a noticeable increase in the Vrd was observed in both lower limbs. The variable Vrd was sensitive to control training effects on sprinting speed in elite soccer players ${ }^{18}$. In this study, this increase could also be considered a positive effect. In relation to the Tc, previously carried out research with 9-year old children found that the lower this parameter was, the greater the running speed. However, no similar trend was observed in our study, once the training program was over. However, in relation to the Tc, although this parameter has been useful to differentiate the fastest 9-year-old children due to a lower $\mathrm{Tc}^{19}$, no clear trend is evident for the $\mathrm{Tc}$ in our two cases as a result of the training program.

This study showed the results of an original rehabilitation approach. The description of the proposed training program and the obtained results could help rehabilitation professionals to develop new physical therapy procedures for children with lower-limb amputation. In this regard, it should be noted that although exercises were designed to improve strength and coordination, and in some ways, a very slight change in gait pattern was expected. The low frequency of training may help explain the relative improvement obtained with the training program.

\section{CONCLUSIONS}

In conclusion, a multidisciplinary training program held once a week for 5 months has shown to be feasible for being carried out in two children with lower-limb amputation. However, its performance had a minimal impact on their walking speed, walking ability, and neuromuscular function.

\section{AUTHORS' CONTRIBUTIONS}

OG and SM: Data curation and formal analysis. DS: Supervision, writing - original draft, and writing - review and editing. CA: Conceptualization and writing - original draft.

\section{REFERENCES}

1. Centomo H, Amarantini D, Martin L, Prince F. Kinematic and kinetic analysis of a stepping-in-place task in below-knee amputee children compared to able-bodied children. IEEE Trans Neural Syst Rehabil Eng. 2007;15(2):258-65. https:// doi.org/10.1109/TNSRE.2007.897005

2. Ashley RK, Vallier GT, Skinner SR. Gait analysis in pediatric lower extremity amputees. Orthop Rev. 1992;21(6):745-9. PMID: 1614721

3. Herbert LM, Engsberg JR, Tedford KG, Grimston SK. A comparison of oxygen consumption during walking between children with and without below-knee amputations. Phys Ther. 1994;74(10):943-50. https://doi.org/10.1093/ ptj/74.10.943

4. Feick $E$, Hamilton PR, Luis $M$, Corbin $M$, Salback NM, Torres-Moreno $\mathrm{R}$, et al. A pilot study examining measures of balance and mobility in children with unilateral lower-limb amputation. Prosthet Orthot Int. 2016;40(1):65-74. https:// doi.org/10.1177/0309364614560941

5. Eshraghi A, Safaeepour Z, Geil MD, Andrysek J. Walking and balance in children and adolescents with lower-limb amputation: A review of literature. Clin Biomech. 2018;59:181-98. https://doi.org/10.1016/j. clinbiomech.2018.09.017

6. Centomo H, Amarantini D, Martin L, Prince F. Differences in the coordination of agonist and antagonist muscle groups in below-knee amputee and able-bodied children during dynamic exercise. J Electromyogr Kinesiol. 2008;18(3):487-94. https:// doi.org/10.1016/j.jelekin.2006.11.008
7. Engsberg JR, Aldridge KC, Harder JA. Lower limb intersegmental forces for below-knee amputee children during standing. Prosthet Orthot Int. 1991;15(3):185-91. https://doi org/10.3109/03093649109164286

8. Bosser G, Martinet N, Rumilly E, Paysant J, André JM. Exercise training for lower limb amputees [Le réentraînement à l'effort chez l'amputé de membre inférieur]. Ann Readapt Med Phys. 2008;51(1):50-6. https://doi.org/10.1016/j.annrmp.2007.09.007

9. Highsmith MJ, Andrews CR, Millman C, Fuller A, Kahle JT, Klenow TD, et al. Gait training interventions for lower extremity amputees: a systematic literature review. Technol Innov. 2016;18(2-3):99-113. https://doi.org/10.21300/18.2-3.2016.99

10. Krajbich Jl. Lower-limb deficiencies and amputations in children. J Am Acad Orthop Surg. 1998;6(6):358-67. https:// doi.org/10.5435/00124635-199811000-00004

11. Treby J, Main E. A survey of physiotherapists involved in paediatric lower limb amputee rehabilitation in the British Isles. Physiotherapy. 2007;93(3):212-7. https://doi.org/10.1016/j.physio.2006.08.007

12. Andrysek J, Klejman S, Steinnagel B, Torres-Moreno R, Zabjek $\mathrm{KF}$, Salbach NM, et al. Preliminary evaluation of a commercially available videogame system as an adjunct therapeutic intervention for improving balance among children and adolescents with lower limb amputations. Arch Phys Med Rehabil. 2012;93(2):358-66. https://doi.org/10.1016/j.apmr.2011.08.031

13. Deathe $A B$, Miller WC. The $L$ test of functional mobility: measurement properties of a modified version of the timed "up \& go" test designed for people with lower-limb amputations. Phys Ther. 2005;85(7):626-35. PMID: 15982169 
14. Simunic B, Degens H, Zavrsnik J, Koren K, Volmut T, Pisot R. Tensiomyographic assessment of muscle contractile properties in 9- to 14-year old children. Int J Sports Med. 2017;38(9):65965. https://doi.org/10.1055/s-0043-110679

15. Granacher U, Lacroix A, Muehlbauer T, Roettger K, Gollhofer A. Effects of core instability strength training on trunk muscle strength, spinal mobility, dynamic balance and functional mobility in older adults. Gerontology. 2013;59(2):105-13. https://doi.org/10.1159/000343152

16. Freeman JA, Gear M, Pauli A, Cowan P, Finnigan C, Hunter $H$, et al. The effect of core stability training on balance and mobility in ambulant individuals with multiple sclerosis: a multi-centre series of single case studies. Mult Scler. 2010;16(11):1377384. https://doi.org/10.1177/1352458510378126
17. Jeans KA, Browne RH, Karol LA. Effect of amputation level on energy expenditure during overground walking by children with an amputation. J Bone Joint Surg Am. 2011;93(1):49-56. https://doi.org/10.2106/JBJS.I.01557

18. Loturco I, Pereira LA, Kobal R, Kitamura K, Ramírez-Campillo $R$, Zanetti $V$, et al. Muscle contraction velocity: a suitable approach to analyze the functional adaptations in elite soccer players. J Sports Sci Med. 2016;15(3):483-91. PMID: 27803627

19. Pišot R, Kerševan K, Djordjević S, Medved V, Završnik J, Šimunič B. Differentiation of skeletal muscles in 9-year-old children. Kinesiol Int J Fundam Appl Kinesiol [Online]. 2004 [cited on Aug. 29, 2020];36(1):90-7. Available from: https:// hrcak.srce.hr/4225 